\section{International Scientific Journal Theoretical \& Applied Science}

p-ISSN: 2308-4944 (print) e-ISSN: 2409-0085 (online)

Year: $2018 \quad$ Issue: 09 Volume: 65
K. V. Gorbyleva candidate of medical sciences associate professor of the department «Normal physiology»

Kyrgyz-Russian Slavic University named after B.N. Yeltsin, Bishkek, Kyrgyzstan

Published: $19.09 .2018 \quad$ http://T-Science.org

\title{
INDICATORS OF THE PSYCHOEMOTIONAL SPHERE OF STUDENTS OF THE MEDICAL PROFILE WITH EXISTENCE OF THE INTERNET ADDICTION
}

\begin{abstract}
Indicators of the psychoemotional sphere at the students with internet addiction studying at medical faculty are surveyed. Over $40 \%$ of addicts have the high level of reactive and personal uneasiness (meets at the female faces of those persons more). Among the above-stated category of surveyed cases of a slight depression (more often at a male) and a subdepression are registered. The vast majority of addictional students (over 70\%), both young men, and girls, possess the inadequate self-rating which is (generally underestimated). The high level of the general aggression reflecting low adaptive opportunities, and introversive orientation of the person at female addicts become perceptible more often.

Key words: students, internet addiction, psychoemotional sphere, young men, girls.

Language: Russian

Citation: Gorbyleva KV (2018) INDICATORS OF THE PSYCHOEMOTIONAL SPHERE OF STUDENTS OF THE MEDICAL PROFILE WITH EXISTENCE OF THE INTERNET ADDICTION. ISJ Theoretical \& Applied Science, 09 (65): 59-62.

Soi: http://s-o-i.org/1.1/TAS-09-65-10 Doi: crossef https://dx.doi.org/10.15863/TAS.2018.09.65.10

\section{ПОКАЗАТЕЛИ ПСИХОЭМОЦИОНАЛЬНОЙ СФЕРЫ СТУДЕНТОВ МЕДИЦИНСКОГО ПРОФИЛЯ С НАЛИЧИЕМ ИНТЕРНЕТ-АДДИКЦИИ}

Аннотация: Рассмотрень показатели психоэмоциональной сферы у студентов с интернетзависимостью, обучающихся на медицинском факультете. Свыше 40\% аддиктов имеют высокий уровень реактивной и личностной тревожности (у лиц женского пола таковых лиц встречается больше). Среди вылеуказанной категории обследуемых регистрируются случаи легкой депрессии (чаше у мужского пола) и субдепрессивного состояния. Подавляющее большинство зависимых студентов (свыше 70\%), как юношей, так и девушек, обладают неадекватной самооценкой (в основном заниженной). Высокий уровень общей агрессии, отражающий низкие адаптивные возможности, и интровертированная направленность личности у аддиктов женского пола отмечаются чащзе.
\end{abstract}

Ключевые слова: студенты, интернет-зависимость, психоэмоциональная сфера, юноши, девушки.

Введение.

Нынешняя ситуация, связанная с лавинообразным развитием интернет-ресурсов и внедрением их практически во все сферы деятельности человека, привела к тому, что участились случаи чрезмерного увлечения глобальной сетью, достигающие болезненного пристрастия [1, с. 232-239], которое оказывает негативное воздействие на психоэмоциональную сферу и межличностные отношения [2, с. 32-35].

Исследование тенденций формирования интернет-зависимости у студентов медицинского университета показывает, что их большинство тратит достаточно времени на виртуальные развлечения и это непременно отражается на их успеваемости, состоянии здоровья, в том числе психического, приводя к изменениям в коммуникативной сфере [3, с. 134], создавая угрозу потери социальных отношений в связи с частым использованием Всемирной Сети $[4$, с. 92].

Авторами выявлено, что эмоциональноволевая сфера интернет-зависимого студенческого контингента характеризуется высокими параметрами личностной тревожности, депрессии, агрессивности, враждебности и 
низкими показателями силы воли, стрессоустойчивости, самооценки, уверенности в себе [5, с. 123]. Студенты, проводящие много времени в сети, имеют достоверно более высокий уровень пессимизма, ригидности и низкий оптимизма, склонны к снижению активности и контактов с людьми [6, с. 16]. Ведущими характеристиками в структуре личности интернет-аддиктов можно считать замедление темпов личностного роста и саморазвития, слабое осознание жизненных целей и перспектив, недооценку собственного потенциала в преодолении жизненных препятствий [7, с. 126127].

\section{Цель исследования.}

Изучение показателей психоэмоциональной сферы студентов медицинского профиля с наличием интернет-аддикции.

\section{Материалы и методы.}

Исследования выполнялись в Лаборатории оптимизации учебного процесса кафедры нормальной физиологии Кыргызско-Российского Славянского университета. С целью выявления интернет-зависимости обследованы студенты младших курсов (юноши $-\mathrm{n}=171$, девушки $\mathrm{n}=271)$ в возрасте 18-20 лет, обучающиеся на медицинском факультете, с использованием опросника Чена, согласно которому выделяются следующие шкалы: 1) Com (компульсивные симптомы); 2) Wit (симптомы отмены); 3) Tol (симптомы толерантности); 4) IH (внутриличностные проблемы и проблемы со здоровьем); ТМ (проблемы с управлением временем), по каждой из них суммируются все пункты и далее выводится общий CIAS балл = $\mathrm{Com}+\mathrm{Wit}+\mathrm{Tol}+\mathrm{IH}+\mathrm{TM}[8$, c. 30-33]. Ha следующем этапе проведен анализ показателей психоэмоциональной сферы лиц, имеющих аддикцию (юноши $-\mathrm{n}=24$, девушки $-\mathrm{n}=23$ ) с применением следующих опросников:

1) Спилбергера-Ханина для исследования уровня тревожности [9, с. 32-33], который является надёжным и информативным способом самооценки уровня тревожности в данный момент (реактивная тревожность как состояние), личностной тревожности (как устойчивой характеристики психики человека);

2) Цунга в целях выявления депрессии [9, с. 34-35], применяющийся с целью дифференциальной диагностики депрессивных состояний и состояний, близких к депрессии, для скрининг-диагностики при массовых обследованиях и в целях предварительной доврачебной диагностики. Опросник состоит из 20 утверждений, содержащих определённые симптомы депрессии. Представленность этих симптомов нужно оценить по шкале: крайне редко, редко, часто, большую часть времени или постоянно;

3) Л.Г. Почебут для диагностики агрессивного поведения [10, с. 383-385] по 5 шкалам:

1. вербальная агрессия (ВА) - человек вербально выражает свое агрессивное отношение к другому человеку, использует словесные оскорбления;

2. физическая агрессия (ФА) - человек выражает свою агрессию по отношению к другому с применением физической силы;

3. предметная агрессия (ПА) - человек срывает свою агрессию на окружающих его предметах;

4. эмоциональная агрессия (ЭА) - у человека возникает эмоциональное отчуждение при общении с другим человеком, сопровождаемое подозрительностью, враждебностью, неприязнью или недоброжелательностью по отношению к нему;

5. самоагрессия (СА) - человек не находится в мире и согласии с собой; у него отсутствуют или ослаблены механизмы психологической защиты, он оказывается беззащитным в агрессивной среде;

4) С.В Ковалёва для определения уровня самооценки, в котором исследуемому предлагаются 32 суждения, а он, выражая степень своего согласия, оценивает их, выбирая один из вариантов ответа, каждый из которых соответствует определенному количеству баллов: 4 - очень часто; 3 - часто; 2 - иногда; 1 - редко; 0 - никогда;

5) К. Юнга для установления типа личности.

Результаты и обсуждение.

Выявление интернет-зависимых лиц показало, что 15,2\% юношей имеют аддикцию, $38 \%$ - склонны к подобному состоянию, а у $46,8 \%$ она не обнаружена. Данные девушек выглядят так: у 11,4\% можно констатировать наличие зависимости, $38 \%$ её не имеют, 50,6\% находятся на доаддиктивном этапе. В ходе оценки уровня реактивной тревожности у обследуемых мужского пола с аддикцией обнаружено, что $12,5 \%$ имеют её низкие значения, 45,8\% - умеренные и 41,7\% - высокие, в то время как у аналогичных лиц женского пола низкий уровень регистрируется в 8,7\% случаев, умеренный $-34,8 \%$, а высокий $-56,5 \%$. Что касается личностной тревожности, то ситуация у представителей вышеуказанных групп выглядит почти идентично, а именно: высокие параметры встречаются у 41,7\% юношей и 47,8\% девушек, умеренные - $41,7 \%$ и $39,1 \%$ соответственно, низкие - $16,6 \%$ против $13,1 \%$ случаев. Показатели двух видов тревожности, 


\section{Impact Factor:}

\begin{tabular}{lr|lr} 
ISRA $($ India $)$ & $=\mathbf{1 . 3 4 4}$ & SIS $($ USA $)$ & $=\mathbf{0 . 9 1 2}$ \\
ISI $($ Dubai, UAE) $=\mathbf{0 . 8 2 9}$ & PИНЦ $($ Russia $)=\mathbf{0 . 1 5 6}$ \\
GIF $($ Australia) & $=\mathbf{0 . 5 6 4}$ & ESJI $($ KZ $)$ & $=\mathbf{4 . 1 0 2}$ \\
JIF & $=\mathbf{1 . 5 0 0}$ & SJIF $($ Morocco $)$ & $=\mathbf{5 . 6 6 7}$
\end{tabular}

выраженные в баллах, между аддиктами обоего

пола достоверно не отличаются (табл. 1).

Таблица 1

Уровень тревожности, депрессии и самооценки у юношей и девушек с интернет-аддикцией

\begin{tabular}{|c|c|c|}
\hline Уровень в баллах & $\begin{array}{c}\text { Юноши } \\
\mathrm{n}=24\end{array}$ & $\begin{array}{c}\text { Девушки } \\
\mathrm{n}=23\end{array}$ \\
\hline Реактивная тревожность & $41,7 \pm 2,1$ & $46,3 \pm 2,5$ \\
\hline Личностная тревожность & $42,7 \pm 2,5$ & $42,4 \pm 2,7$ \\
\hline Депрессия & $40,3 \pm 2,04$ & $38,1 \pm 1,9$ \\
\hline Самооценка & $54,25 \pm 3,7$ & $53,6 \pm 5,6$ \\
\hline
\end{tabular}

Рассматривая значения уровня депрессии среди интернет-зависимых лиц, стоит отметить, что в обеих группах выявлены случаи легкой депрессии (в 3 раза чаще встречающиеся у юношей - $12,5 \%$ против 4,3\%) и субдепрессивного состояния $\quad(4,2 \%$ и $\quad 4,3 \%$ соотвественно). Параметры в баллах практически схожи (табл. 1). Говоря об уровне самооценки, можно выделить следующие особенности: адекватные её значения имеет только $1 / 4$ часть обследуемых (25 \% юношей и 22,7\% девушек), подавляющее же большинство характеризуется ее низким уровнем $(66,7 \%$ и $63,6 \%$ соответственно) и у небольшой группы она высокая (среди 8,3\% юношей и $13,7 \%$ девушек). При сравнении балльных значений показателя самооценки достоверных различий не обнаружено (табл. 1).

\section{Уровень агрессии у юношей и девушек с интернет-аддикцией}

Таблица 2

\begin{tabular}{|c|c|c|}
\hline Уровень агрессии в баллах & $\begin{array}{c}\text { Юноши } \\
\mathrm{n}=24\end{array}$ & $\begin{array}{c}\text { Девушки } \\
\mathrm{n}=23\end{array}$ \\
\hline Вербальная & $2,75 \pm 0,3$ & $3,2 \pm 0,4$ \\
\hline Физическая & $4,04 \pm 0,36$ & $2,7 \pm 0,4^{*}$ \\
\hline Предметная & $2,8 \pm 0,3$ & $4 \pm 0,4^{*}$ \\
\hline Эмоциональная & $2,4 \pm 0,3$ & $2,2 \pm 0,3$ \\
\hline Самоагрессия & $3,4 \pm 0,5$ & $3,26 \pm 0,4$ \\
\hline Общая & $15,2 \pm 1,1$ & $15,3 \pm 1,3$ \\
\hline
\end{tabular}

Примечание: показатель статистически достоверен при: * $\mathrm{P}<0,05$.

При оценке агрессивного поведения обнаружено, что значения предметной агрессии, выраженные в баллах (табл. 2), достоверно выше у интернет-зависимых девушек по сравнению с таковыми юношами $(4 \pm 0,4$ и $2,8 \pm 0,3$ соответственно), а физической - у последних (4 $\pm 0,36$ против $2,7 \pm 0,4)$. Высокий уровень общей агрессии, демонстрирующий низкие адаптивные возможности, чаще встречается у аддиктов женского пола $(8,7 \%$ против $4,2 \%), \quad$ a самоагрессии - у мужского $(25 \%$ и $17,4 \%$ соответственно). Исследование типа личности показал, что практически половина интернетзависимых девушек являются амбивертами $(45,5 \%), \quad 31,8 \%$ обследуемых приходится на экстравертов, в то время как у юношей ситуация выглядит несколько иначе: 70,9\% относятся к амбивертам, 20,8\% - к экстравертам, а вот интровертированная направленность личности у девушек-аддиктов выявлена почти в 3 раза чаще (22,7\% против 8,3\%).

\section{Выводы.}

Таким образом, анализ психоэмоциональной сферы интернет-зависимых студентов медицинского профиля позволил выделить своего рода контуры лиц, относящихся к данному контингенту, который независимо от пола, достаточно тревожен, депрессивен, имеет низкую самооценку, старается находиться в своем собственном виртуальном мире и меньше контактировать с окружающими. Полученные данные являются одним из фрагментов, составляющих сложную мозаику личностных изменений аддикта, и требуют дальнейшего изучения. Результаты проведенного исследования указывают на необходимость разработки плана коррекционных и профилактических мероприятий. 


\begin{tabular}{|c|c|c|c|c|c|c|}
\hline Impact Factor: & $\begin{array}{l}\text { ISRA (India) } \\
\text { ISI (Dubai, UAE } \\
\text { GIF (Australia) } \\
\text { JIF }\end{array}$ & $\begin{array}{r}=1.344 \\
=0.829 \\
=0.564 \\
=1.500\end{array}$ & $\begin{array}{l}\text { SIS (USA) } \\
\text { PИHЦ (Russia) } \\
\text { ESJI (KZ) } \\
\text { SJIF (Morocco) }\end{array}$ & $\begin{array}{l}=0.912 \\
=0.156 \\
=4.102 \\
=2.031\end{array}$ & $\begin{array}{l}\text { ICV (Poland) } \\
\text { PIF (India) } \\
\text { IBI (India) }\end{array}$ & $\begin{array}{l}=6.630 \\
=1.940 \\
=4.260\end{array}$ \\
\hline
\end{tabular}

\section{References:}

1. Larionova S.O., Degterev A.S. (2013) Internetzavisimost' u studentov: voprosy profilaktiki. Pedagogicheskoe obrazovanie v Rossii. 2013; 2: 232-239.

2. Grigor'eva O.V., Vanjuhina N.V. (2014) Psihojemocional'naja sfera podrostkov $\mathrm{s}$ zavisimost'ju ot interneta. Azimut nauchnyh issledovanij: pedagogika i psihologija. 2014; 3 : 32-35.

3. Vanjushina E.A., Goncharova M.A. (2017) Sovremennye tendencii formirovanija internetzavisimosti u studentov medicinskogo universiteta. Bjulleten' nauki i praktiki. 2017; 3: 134-138.

4. Ivanova A.M., Hoda L.D. (2015) Osobennosti kommunikativnyh navykov i samoocenki u studentov s internet-zavisimost'ju. Nauchnye issledovanija i razrabotki molodyh uchenyh. 2015; 5: 89-92.

5. Alekseenko V.V. (2013) Internet-zavisimost' i jemocional'no-volevaja sfera lichnosti studentov. Lichnost' v izmenjajushhihsja social'nyh uslovijah: sbornik statej II
Mezhdunarodnoj nauchno-prakticheskoj konferencii. 6-8 nojabrja 2013. Krasnojarsk; 2013: 119-123.

6. Bashkina A.S. Noskova M.P. (2017) Specifika profilja lichnosti studentov $\mathrm{s}$ addiktivnym povedeniem $\mathrm{V}$ internet-srede. Bezopasnost' zdorov'ja cheloveka. 2017; 3: 14-17.

7. Ershova R.V., Semina T.M. (2016) Lichnostnye osobennosti internet-zavisimyh studentov. Cifrovoe obshhestvo kak kul'turno-istoricheskij kontekst razvitija cheloveka: sbornik nauchnyh statej i materialov mezhdunarodnoj konferencii. 11-13 fevralja 2016. Kolomna; 2016: 126-127.

8. (2011) Internet-zavisimoe povedenie. Kriterii i metody diagnostiki: Uchebnoe posobie. M.: MGMSU; 2011. 32.

9. Karelin A.A. (2007) Bol'shaja jenciklopedija psihologicheskih testov. M.: Jeksmo; 2007. 416.

10. Platonov Yu.P. (2003) Osnovy etnicheskoy psikhologii: Uchebnoe posobie. St. Petersburg: Speech; 2003. 456. (in Russian). 